\title{
Learning from instruction: the case of mathematics
}

\author{
Erik De Corte
}

Received: 28 December 2006/ Accepted: 10 January 2007/Published online: 15 March 2007

(C) Springer Science+Business Media, LLC 2007

\begin{abstract}
Starting from a brief analysis of adaptive competence in mathematics, this article describes a series of research-based characteristics of the kind of learning processes that should be elicited in students to facilitate and support in them the progressive acquisition of such competence. Four major characteristics are discussed in some detail: learning is constructive, self-regulated, situated or contextual, and collaborative. A rather new approach to transfer of learning is then presented in which transfer is conceived as the preparation for future learning. Throughout the article it is argued that, notwithstanding the progress made in research on learning from instruction, numerous and complex issues and problems remain for continued inquiry.
\end{abstract}

Keywords Adaptive competence $\cdot$ Mathematics learning $\cdot$ Transfer of learning

In their chapter on 'Learning Theories and Education: Toward a Decade of Synergy' in the recently published Handbook of Educational Psychology. Second Edition, Bransford et al. (2006) distinguish between three strands in research on learning: (1) implicit learning and the brain; (2) informal learning; and (3) designs for formal learning and beyond. Learning from instruction which constitutes the core of instructional psychology converges largely with the third strand which involves according to Bransford et al. (2006)

"the use of knowledge about learning to create designs for formal learning and beyond (where 'beyond' includes ideas for school redesign and connections to informal learning activities), and to study of the effects of these designs to further inform theoretical development" (p. 221)

E. De Corte $(\bowtie)$

Center for Instructional Psychology and Technology (CIP\&T), University of Leuven,

Vesaliusstraat 2, 3000 Leuven, Belgium

e-mail: erik.decorte@ped.kuleuven.be 
It derives from this perspective on formal learning (1) that identifying and advancing our knowledge of learning is crucial, and (2) that design-based research is an appropriate avenue to advancing this knowledge. In this article I will focus on the first issue; thereby I will focus on the subject-matter domain of mathematics (for a brief discussion of design research see Phillips \& Dolle, 2006). As a starting point it is useful to situate 'knowledge about learning' in a broader conceptual framework about learning from instruction.

In the CLIA-model-a framework for the design of powerful learning environments (De Corte, Verschaffel, \& Masui, 2004)—we distinguish four interconnected components in a theory of learning from instruction:

(1) Competence: what are the components of competence in a domain, more specifically in mathematics?

(2) Learning: what kinds of learning/developmental processes have to be induced in students to facilitate their acquisition of competence?

(3) Intervention: what are appropriate instructional methods and environments to elicit and maintain in students the required learning and developmental processes?

(4) Assessment: which types of instruments are necessary to assess students' mastery of the components of competence?

In view of searching for and deciding on the kinds of learning processes that should be elicited in students, it is necessary to define what they have to acquire, for instance, in a mathematics course, in other words to determine what it means to become competent in a domain such as mathematics.

\section{A brief analysis of (mathematical) competence}

There is currently a broad consensus among scholars in the field of mathematics education (see e.g., De Corte \& Verschaffel, 2006; National Research Council, 2001) that becoming competent in mathematics can be conceived of as acquiring a mathematical disposition. Building up and mastering such a disposition requires the acquisition of five categories of cognitive, affective, and cognitive components (for a more detailed discussion of some of these components see De Corte \& Verschaffel, 2006):

(1) A well-organized and flexibly accessible domain-specific knowledge base involving the facts, symbols, algorithms, concepts, and rules that constitute the contents of mathematics as a subject-matter field.

(2) Heuristic methods, i.e., search strategies for problem analysis and transformation (e.g., decomposing a problem into subgoals, making a graphic representation of a problem) which do not guarantee, but significantly increase the probability of finding the correct solution.

(3) Meta-knowledge, which involves knowledge about one's cognitive functioning (metacognitive knowledge; e.g., knowing that one's cognitive potential can be developed through learning and effort), on the one hand, and knowledge about one's motivation and emotions (metavolitional knowledge; e.g., becoming aware of one's fear of failure when confronted with a complex mathematical task or problem), on the other hand. 
(4) Positive mathematics-related beliefs, which include the implicitly and explicitly held subjective conceptions about mathematics education, about the self as a learner of mathematics, and about the social context of the mathematics classroom.

(5) Self-regulatory skills, which embrace skills relating to the self-regulation of one's cognitive processes (metacognitive skills or cognitive self-regulation; e.g., planning and monitoring one's problem-solving processes), on the one hand, and skills for regulating one's volitional processes/activities (metavolitional skills or volitional self-regulation; e.g., keeping up one's attention and motivation to solve a given problem), on the other hand.

However, research has shown that knowledge and skills that are available in students are often accessible nor usable when necessary to solve a new, unfamiliar problem (Cognition and Technology Group at Vanderbilt, 1997). Acquiring a disposition to skilled learning and thinking should help to overcome this phenomenon of inert knowledge. Therefore, the integrated mastery of the different components mentioned above should result in the development of a disposition toward skilled thinking and learning. According to Perkins (1995) such a disposition involves besides ability and motivation, two additional crucial aspects, namely sensitivity for situations in which it is relevant and appropriate to use acquired knowledge and skills, and an inclination to do so.

Using a different construct that was introduced in the literature more than two decades ago by Hatano (1982; see also Hatano \& Inagaki, 1986), one can say that students have to acquire 'adaptive expertise' as opposed to 'routine expertise.' In his foreword of the book The development of arithmetic concepts and skills. Constructing adaptive expertise edited by Baroody and Dowker (2003), Hatano (2003, p. xi) describes adaptive expertise as "the ability to apply meaningfully learned procedures flexibly and creatively;" in contrast routine expertise involves "simply being able to complete school mathematics exercises quickly and accurately without (much) understanding" (p. xi). In a recent article Hatano and Oura (2003) propose the notion of 'adaptive expertise' as a valuable concept to understand students' learning and development in curricular domains and as a relevant principle for the effective design of instruction in schools. Compared to the well-established cognitive perspective to expert-novice differences and to teaching for expertise, Hatano and Oura (2003) present a broader view of expertise development that includes socioemotional and sociocultural aspects. This is exemplified by their emphasis on the observation that the process of gaining (adaptive) expertise always occurs in particular sociocultural contexts and is accompanied by changes in interest, values and identity (besides changes in the cognitive realm).

Besides this broader view of adaptive expertise, it is important from the perspective of learning that according to Bransford et al. (2006) both routine and adaptive experts continue to learn throughout their lifetimes. But whereas routine experts mainly learn to use their competencies with increasing efficiency, adaptive expertise "involves the willingness and ability to change core competencies and continually expand the breadth and depth of one's expertise."' (p. 223)

Anticipating on an issue that I will come to later in this article, it seems that acquiring a mathematical disposition or adaptive expertise-which could also be called 'adaptive competence'-is important, if not necessary, in view of the acquisition of the ability to transfer one's knowledge and skills to new tasks and learning contexts. 


\section{Implications for and characteristics of productive learning}

The view of (adaptive) mathematical competence described above has implications for the kind of learning processes that have to be elicited in students to facilitate the progressive acquisition of the intended competence. Over the past decade a substantial amount of books that synthesize/summarize the relevant literature in this respect were published, besides the already mentioned Handbook of Educational Psychology. Second Edition (Alexander \& Winne, 2006): the first edition of the Handbook of Educational Psychology (Berliner \& Calfee, 1996); How People Learn (National Research Council, 2000); New Learning (Simons, van der Linden, \& Duffy, 2000a); Adding it up: Helping Children Learn Mathematics (National Research Council, 2001); How Students Learn: History, Mathematics, and Science in the Classroom (National Research Council, 2005).

Traditionally the dominant form of learning in schools has been teacher-directed learning, or-as called by Simons, van der Linden, and Duffy (2000b)—guided learning:

"a trainer or teacher takes all the relevant decisions and the learner can and should follow him or her. He decides about the goals of learning, the learning strategies, the way to measure outcomes and he takes care of feedback, judgments, and rewards." (p. 4)

Taking into account that adaptive competence which involves skills in self-regulating one's learning processes, is now considered as the ultimate goal of mathematics education, it is obvious that guided learning is not, and certainly not the only appropriate way of learning in view of achieving such competence. Relevant in this regard is that Simons et al. (2000b) distinguish besides guided learning two other ways of learning, namely experiential and action learning. In contrast to guided learning experiential learning is not controlled by a teacher and has not predetermined objectives, but what is learned is determined by the context, one's motivation, the others in the learning situation, new discoveries made, etc.; what is acquired is a by-product of the activities in which one is involved. Again to the contrary, action learning is not a by-product, but the learner plays a much more active role in determining the objectives of his or her learning; in other words, learning is largely self-organized and self-planned.

In line with the point of view of Simons et al. (2000b), I like to argue that to facilitate and support in learners the gradual and progressive acquisition of adaptive mathematical competence, novel classroom practices and cultures are needed that create the conditions for a substantial shift from guided learning toward experiential as well as action learning, resulting in a balanced and integrated use of the three ways of learning. Such a balance allows for structure and guidance by the teacher where needed, creates space for substantial self-regulated and self-determined learning by students, but leaves also open opportunities for what Eisner (1994) has called expressive outcomes, i.e., unanticipated results of open and incidental encounters in a variety of situations, be it in a museum, a forest, etc. To realize the required shift, I have argued (De Corte, 1996) — taking into account Shuell's (1988) point of view about good learning - that school learning in general-and thus also mathematics learning-needs to embody more than was traditionally the case the characteristics summarized in the following definition: it is an active/constructive, cumulative, self-regulated, goal-directed, situated, collaborative, and individually 
different process of meaning construction and knowledge building (see also Mayer, 2001; National Research Council, 2000). Simons et al. (2000b) mention an even more extended list of characteristics: a shift toward action learning requires more active, more cumulative, more constructive, more goal-directed, more diagnostic, and more reflective learning; a shift toward experiential learning requires more discoveryoriented, more contextual, more problem-oriented, more case-based, more social, and more intrinsically motivated learning. In a booklet in the "Educational Practices Series" of the International Academy of Education entitled How children learn, Vosniadou (2001) has summarized the empirical evidence supporting most of these characteristics of productive learning. More specifically, she presents the research findings underlying the following 12 principles of learning and their relevance for education: (1) active involvement; (2) social participation; (3) meaningful activities; (4) relating new information to prior knowledge; (5) being strategic; (6) engaging in self-regulation and being reflective; (7) restructuring prior knowledge; (8) aiming toward understanding rather than memorization; (9) helping students learn to transfer; (10) taking time to practice; (11) developmental and individual differences; and (12) creating motivated learners. An important principle in this list that is not explicitly mentioned above is the emphasis on understanding; in other words, in learning and teaching domain-specific knowledge the focus should be on conceptual knowledge, but where relevant connected and integrated with procedural knowledge (De Corte \& Verschaffel, 2006: see also Baroody \& Dowker, 2003). Another principle in Vosniadou's list to which I will come back later is that students should learn to transfer.

\section{Productive learning: constructive, self-regulated, contextual, and collaborative}

It is not possible to discuss here in detail all those characteristics and principles of the learning processes that need to be elicited in students to facilitate and support in them the acquisition of adaptive mathematical competence. I will therefore restrict myself to a brief critical discussion of four aspects that are especially relevant, namely learning is constructive, self-regulated, situated or contextual, and collaborative.

\section{Learning is constructive}

The constructivist view of learning has nowadays become more or less common ground among educational psychologists (see e.g., Phillips, 2000; Simons, van der Linden, \& Duffy, 2000a; Steffe \& Gale, 1995). But, what does this exactly mean? Indeed, there is today strong evidence that learning is in some sense always constructive, even in environments that embody a dominantly guided learning approach. This is convincingly demonstrated by the robust research results showing the occurrence of misconceptions (such as "multiplication makes bigger"), and defective procedural skills (such as buggy algorithms) among students in traditional mathematics classrooms; as argued by Hatano (1996): "it is very unlikely that students have acquired them by being taught" (p. 201). What is essential in the constructivist perspective on learning is the mindful and effortful involvement of students in the processes of knowledge and skills acquisition in interaction with the environment. In this respect, Greer (1996; see also Hatano, 1996) has quite rightly claimed that what needs to be (re)constructed is the process of doing mathematics rather than the 
mathematical content. However, as described by Phillips (1995) in an article entitled 'The good, the bad, and the ugly: The many faces of constructivism,' there are in the literature many versions of constructivism, spanning a wide variety of theoretical and epistemological perspectives, and differing in many important respects from one another. This holds still true today, so that at present we certainly cannot claim to have already a full-fledged, research-based constructivist learning theory. As already argued by Fischbein in 1990, there is a need for a "more specific definition of constructivism as a psychological model for mathematics education" (p. 12). In other words, the present state-of-the-art calls for continued theoretical and empirical research aimed at a deeper understanding and a more fine-grained analysis of the nature of constructive learning processes that are conducive to the acquisition of worthwhile knowledge, (meta)cognitive strategies, and affective components of adaptive competence, and of the role and nature of instruction in eliciting and facilitating such learning processes.

\section{Learning is self-regulated}

Especially because the process and not the product of learning is the focus of constructivism, this perspective implies that constructive learning is self-regulated. Indeed, self-regulation "refers to the degree that individuals are metacognitively, motivationally, and behaviorally active participants in their own learning process" (Zimmerman, 1994, p. 3). Although research on academic self-regulation began only about 20 years ago, a substantial amount of empirical and theoretical work has already been carried out, and has led to interesting and relevant results (for a detailed overview see Boekaerts, Pintrich, \& Zeidner, 2000; see also National Research Council, 2000, 2005; Simons et al., 2000). First, major characteristics of self-regulated learners have been identified: they manage study time well, set higher specific and proximal goals, monitor more frequently and accurately, set a higher standard for satisfaction, are more self-efficacious, and persist despite obstacles. Furthermore, it has also been established in a variety of content domains, including mathematics, that the degree of self-regulation correlates strongly with academic achievement (Zimmerman \& Risemberg, 1997), and that self-regulatory processes can be enhanced through appropriate intervention (Boekaerts et al., 2000). Nevertheless, there is still a need for continued research aiming at a better understanding of the major processes involved in self-regulating school learning effectively, at tracing the development of regulatory skills in students, and at unraveling how and under what instructional conditions students become self-regulated learners, in other words, how do they learn to manage and monitor their own processes of knowledge building and skill acquisition, or how can the transition from external regulation (by a teacher) to self-regulation be enhanced. Related to the latter aspect is the important question concerning the interaction between domain-specific competence and self-regulation: does (successful) regulation of academic learning in a given content domain require a certain degree of competence in that domain (Alexander, 1995)?

Learning is contextual or situated

A nowadays widely shared idea in educational research circles in general, and in the mathematics education community in particular, is also that constructive and selfregulated learning processes should preferably happen and be studied in context, i.e., 
in relation to the social, contextual, and cultural environment and factors in which these processes are embedded and that influence them (for a thorough overview see Kirschner \& Whitson, 1997; see also National Research Council, 2000, 2005). In the late 1980s the importance of contextual factors for learning has been highlighted by the situated cognition and learning paradigm that emerged in reaction to the mentalistic/computational view of learning and thinking as highly individual and purely cognitive processes occurring in the head, and resulting in the construction of encapsulated mental representations (Brown, Collins, \& Duguid, 1989). Generally speaking, situativity theory has quite rightly stressed that learning is enacted essentially in interaction with the social and cultural contexts and artifacts, and especially through participation in cultural activities and contexts (see also Bruner, 1996; Greeno, Collins, \& Resnick, 1996). With respect to mathematics this situativity perspective has fueled and supported the movement toward more authentic and realistic mathematics education. However, the situated cognition perspective has also been criticized for being only "a 'loosely coupled' school of thought" (Gruber, Law, Mandl, \& Renkl, 1995, p. 177), for making inaccurate and overstated claims from which inappropriate educational implications are derived (Anderson, Reder, \& Simon, 1996), and for downgrading or at least not appropriately addressing the role of knowledge in learning (Vosniadou, 2005; Vosniadou \& Vamvakoussi, 2006). Besides, because of the dual nature of mathematics-i.e., its grounding in reality and its usefulness for solving practical problems, on the one hand, and its abstract nature, on the other-mathematics education should pursue the acquisition of formal, conceptual knowledge that goes beyond the specific situation in which it was first acquired. Taking all this into account, it is obvious that there is a strong need for further theoretical inquiry and empirical research aiming at a new synthesis integrating the positive aspects of both world, cognitive psychology and situativity theory (see also Vosniadou, 1996).

\section{Learning is collaborative}

The collaborative nature of learning is implied in the situativity perspective. Indeed, situativity theory stresses the social character of learning. This means that effective learning is not a purely "solo" activity, but essentially a distributed one, i.e., the learning efforts are distributed over the individual student, his partners in the learning environment, and the (technological) resources and tools that are available (Salomon, 1993). The conception of learning as a social process is also central to socalled socioconstructivism; it accounts for the observation that, notwithstanding the almost idiosyncratic processes of knowledge building, learners nevertheless acquire shared concepts and skills (Ernest, 1996). For instance, Wood, Cobb, and Yackel (1991) consider social interaction essential for mathematics learning, with individual knowledge construction occurring throughout processes of interaction, negotiation, and cooperation. There is no doubt that the available literature provides substantial evidence supporting the positive effects of collaborative learning on academic achievement (see e.g., Lehtinen, 2003; Salomon, 1993; van der Linden, Erkens, Schmidt, \& Renshaw, 2000), and that a shift toward more social interaction in mathematics classrooms would represent a worthwhile move away from the traditional overemphasis on individual learning. However, one should also avoid falling into the other extreme. Indeed, stressing the importance for learning of collaboration and interaction does not at all exclude that students can and do also develop 
new knowledge individually. As argued by Salomon and Perkins (1998; see also Sfard, 1998), distributed and individual cognitions interact during productive learning. But, in addition, there remain numerous unanswered questions relating to collaborative learning in small groups. According to Webb \& Palincsar (1996) the most substantive accomplishment of research is the recognition of the complexities of designing, implementing, and evaluating learning and problem solving in groups. Due to these complexities it is hard to draw clear conclusions from the available studies. For instance, we need a better understanding of the way in which smallgroup activities influence students' learning and thinking, of the role of individual differences on group work, and of the mechanisms that are at work during group processes (see also van der Linden et al., 2000).

\section{Reconceptualizing transfer of learning}

As mentioned above, one of the 12 principles presented by Vosniadou (2001) in her booklet How children learn is 'helping students learn to transfer.' This is not surprising. Indeed, throughout history educators have always attempted to equip students with cognitive tools that they can apply beyond the initial learning situation. And, currently transfer of acquired knowledge and skills is still considered as an important goal of education (National research Council, 2000). With respect to mathematics, it is expected that students will be able to use their acquired knowledge and skills to solve mathematics-related situation and problems in everyday life. The scientific study of transfer dates back to the beginning of the previous century. But from the beginning the concept has been very controversial, conceptually as well as empirically (for a brief history and suggestions for further reading see e.g., De Corte, 1999).

An analysis of the relevant literature reveals that traditionally transfer was very narrowly conceived as the independent and immediate application of knowledge and skills acquired in one situation to another. Accordingly, narrow criteria of successful transfer were adopted. Bransford and Schwartz (1999) called this narrow definition the direct-application theory of transfer, the key question being, Can people apply something they learned directly and independently to a new setting? A typical characteristic of this approach to transfer is that the final transfer task (i.e., the experimental task used to test whether transfer has taken place) takes the form of 'sequestered problem solving.' That is, while solving the transfer task, subjects do not get opportunities to invoke support from other resources, such as texts or colleagues, or to try things out, receive feedback, or revise their work.

As an alternative to this view, Bransford and Schwartz (1999; see also Bransford et al., 2006) proposed a broader perspective emphasizing preparation for future learning $(P F L)$ as the major aspect of transfer. Under this framework, the focus in assessing transfer is on subjects' abilities to learn in novel, resource-rich contexts. This view is much more in line with the now-prevailing notion of learning as an active and constructive process, but emphasizes in addition the active nature of transfer itself. Indeed, in this approach a novel context is not conceived as just "given"; using one's prior knowledge and the available resources, one can modify the situation and its perception. For instance, confronted with a fellow learner's perspective about a problem situation, one can revise one's own perception of the problem. In this respect, Bransford and Schwartz also emphasized the important role 
of metacognitive (or self-regulatory) skills. Such active control of the transfer situation is lacking in the direct-application model. Another benefit of the PFL model of transfer is that it suggests affective and motivational qualities, in addition to cognitive skills, are candidates for transfer.

The PFL approach is convergent with a redefinition of transfer by Hatano and Greeno (1999), who criticized traditional models of transfer for both treating knowledge as a static property of an individual and adopting inappropriately narrow criteria of successful transfer. They considered the conceptualization of transfer as the direct application of acquired elements from one situation to another as incompatible with current perspectives on the contextualized nature of knowledge and learning. That is, the direct-application theory is static, in the sense that it neglects how aspects of thinking that arise from interactions among people, and between people and other material and informational systems, might affect performance in the transfer situation. Hatano and Greeno proposed replacing the term transfer with the term productivity, to refer to the generality of learning (i.e., the degree to which learning in some situation has effects on task-related activities in a variety of other situations). The latter situations can-in accordance with the PFL perspective-involve hints or other kinds of support that facilitate the recall of relevant prior knowledge.

There is thus a strong tendency toward reconceptualizing transfer, emphasizing the broad, flexible, productive, and supported use of acquired knowledge, skills, and motivations, as opposed to the direct and sequestered application of skills from one situation to another. Stated differently, learning to transfer requires or involves the acquisition of adaptive expertise (in mathematics but similarly in other content domains) (see also Hatano \& Oura, 2003). It is obvious that this new perspective on transfer has important implications for fostering in students the preparation for future learning. And, because this reconceptualization is in accordance with a constructivist and situated perspective on learning, these implications are in line with features of powerful learning environments in general, and can be summarized as follows: starting as much as possible from tasks and problems that are meaningful and challenging for students, learning environments should initiate socially supported constructive learning processes that enhance students's cognitive and volitional self-regulatory skills (De Corte, 2004). There is now already empirical evidence from design research showing that immersing students in such learning environments can boost their ability to productively apply their knowledge and skills, and thus enhance their preparedness to approach new learning tasks and problems more effectively (De Corte, 2003).

\section{Conclusion}

The available research provides already fairly good support for the view that effective and worthwhile mathematics learning from instruction that aims at fostering adaptive competence in students, is a constructive, self-regulated, situated, and collaborative process of knowledge building and skill acquisition. However, this state-of-the-art should not lead to a kind of self-complacency among mathematics education scholars, but should rather motivate the research community to continue its endeavors. Indeed, notwithstanding the past achievements, the preceding brief analysis shows that numerous and complex issues and problems remain to be studied 
and solved with a view to the elaboration of a more thorough, explanatory theory of mathematics learning processes that facilitate the acquisition of adaptive mathematical competence in students, and of the instructional conditions in the learning environment that support these learning processes.

Criticisms on the traditional view of transfer have recently led to the emergence of a reconceptualization of this construct as the preparation for future learning and the productive and flexible application of one's knowledge, skills, and motivations. The relevance of this new perspective has already been demonstrated in intervention studies. But transfer is a complex phenomenon due to the involvement of several interacting categories of variables, namely, learner characteristics, learning and transfer tasks, and instructional and transfer contexts. Therefore, here also continued inquiry is needed, and should aim at (1) a better understanding of the processes underlying transfer; (2) unraveling the components of learning environments that facilitate the productive use of acquired knowledge, skills, and motivations; and (3) the design of alternative forms for assessing transfer.

\section{References}

Alexander, P. A. (1995). Superimposing a situation-specific and domain-specific perspective on an account of self-regulated learning. Educational Psychologist, 30, 189-193.

Alexander P. A., \& Winne P. H. (Eds.) (2006). Handbook of educational psychology (Second edition). Mahwah, NJ: Lawrence Erlbaum Associates.

Anderson, J. R., Reder, L. M., \& Simon, H .A. (1996). Situated learning and education. Educational Researcher, 25(4), 5-11.

Baroody A. J., \& Dowker A. (Eds.) (2003). The development of arithmetic concepts and skills. Constructing adaptive expertise. Mahwah, NJ: Lawrence Erlbaum Associates.

Berliner D. C., \& Calfee R. C. (Eds.) (1996). Handbook of educational psychology. New York: Macmillan.

Boekaerts, M., Pintrich, P .R., \& Zeidner, M. (2000). Handbook of self-regulation. San Diego: Academic Press.

Bransford, J. D., \& Schwartz, D. L. (1999). Rethinking transfer: A simple proposal with multiple implications. In: A. Iran-Nejad \& P.D. Pearson (Eds.), Review of research in education: Vol. 24. (pp. 61-100). Washington, DC: American Educational Research Association.

Bransford, J., Stevens, R., Schwartz, D., Meltzoff, A., Pea, R., Roschelle, J., Vye, N., Kuhl, P., Bell, P., Barron, B., Reeves, B., \& Sabelli, N. (2006). Learning theories and education: Toward a decade of synergy. In: P. A. Alexander \& P. H. Winne (Eds.), Handbook of educational psychology. Second edition (pp. 209-244). Mahwah, NJ: Lawrence Erlbaum Associates.

Brown, J. S., Collins, A., \& Duguid, P. (1989). Situated cognition and the culture of learning. Educational Researcher, 18(1), 32-42.

Bruner, J. (1996). The culture of education. Cambridge, MA: Harvard University Press.

Cognition and Technology Group at Vanderbilt (1997). The Jasper Project: Lessons in curriculum, instruction, assessment, and professional development. Mahwah, NJ: Lawrence Erlbaum Associates.

De Corte, E. (1996). Instructional psychology: Overview. In: E. De Corte \& F. E. Weinert (Eds.), International encyclopedia of developmental and instructional psychology (pp. 33-43). Oxford, UK: Elsevier Science Ltd.

De Corte, E. (Ed.) (1999). On the road to transfer: New perspectives on an enduring issue in educational research and practice [Thematic issue]. International Journal of Educational Research, 31, 553-654.

De Corte, E. (2003). Designing learning environments that foster the productive use of acquired knowledge and skills. In: E. De Corte, L. Verschaffel, N. Entwistle, \& J. van Merriënboer (Eds.), Powerful learning environments: Unraveling basic components and dimensions (pp. 21-33). Oxford, UK: Elsevier Science Ltd. (Advances in Learning and Instruction Series). 
De Corte, E. (2004). Mainstreams and perspectives in research on (mathematics) learning from instruction. Applied Psychology: An International Review, 53, 279-310.

De Corte, E., \& Verschaffel, L. (2006). Mathematical thinking and learning. In: K. A. Renninger, I. E. Sigel (Series Eds.), W. Damon, R. M. Lerner (Eds-in-Chief.), Handbook of child psychology, Volume 4: Child psychology and practice (6th ed., pp. 103-152). Hoboken, NJ: John Wiley \& Sons.

De Corte, E., Verschaffel, L., \& Masui, C. (2004). The CLIA-model: A framework for designing powerful learning environments for thinking and problem solving. European Journal of Psychology of Education, 19, 365-384.

Eisner, E. W. (1994). The educational imagination. On the design and evaluation of school programs. Third edition. New York: Macmillan.

Ernest, P. (1996). Varieties of constructivism: A framework for comparison. In: L. P. Steffe, P. Nesher, P. Cobb, G. A. Goldin, \& B. Greer (Eds.), Theories of mathematical learning (pp. 335-350). Mahwah, NJ: Lawrence Erlbaum Associates.

Fischbein, E. (1990). Introduction. In: P. Nesher \& J. Kilpatrick (Eds.), Mathematics and cognition: A research synthesis by the International Group for the Psychology of Mathematics Education (pp. 1-13). Cambridge, UK: Cambridge University Press. (ICMI Study Series).

Greeno, J. G., Collins, A. M., \& Resnick, L. B. (1996). Cognition and learning. In: D. C. Berliner \& R. C. Calfee (Eds.), Handbook of educational psychology (pp. 15-46). New York, NY: Macmillan.

Greer, B. (1996). Theories of mathematics education: The role of cognitive analysis. In: L. Steffe, P. Nesher, P. Cobb, G. A. Goldin, \& B. Greer (Eds.), Theories of mathematical learning (pp.179196). Mahwah, NJ: Lawrence Erlbaum Associates.

Gruber, H., Law, L. C., Mandl, H., \& Renkl, A. (1995). Situated learning and transfer. In: P. Reimann \& H. Spada (Eds.), Learning in humans and machines. Towards an interdisciplinary learning science (pp. 168-188). Oxford, UK: Elsevier Science Ltd.

Hatano, G. (1982). Cognitive consequences of practice in culture specific procedural skills. The Quartely Newsletter of the Laboratory of Comparative Human Cognition, 4, 15-18.

Hatano, G. (1996). A conception of knowledge acquisition and its implications for mathematics education. In: L. P. Steffe, P. Nesher, P. Cobb, J. Kilpatrick, \& B. Greer (Eds.), Theories of mathematical learning (pp. 197-217). Mahwah, NJ: Lawrence Erlbaum Associates.

Hatano, G. (2003). Foreword. In: A. J. Baroody \& A. Dowker (Eds.), The development of arithmetic concepts and skills: Constructing adaptive expertise (pp. XI-XIII). Mahwah, NJ: Lawrence Erlbaum Associates.

Hatano, G., \& Greeno, J. G. (1999). Commentary: Alternative perspectives on transfer and transfer studies. International Journal of Educational Research, 31, 645-654.

Hatano, G., \& Inagaki, K. (1986). Two courses for expertise. In: H. Stevenson, H. Azuma, \& K. Hakuta (Eds.), Child development and education in Japan (pp. 262-272). New York: Freeman.

Hatano, G., \& Oura, Y. (2003). Commentary reconceptualizing school learning using insight from expertise research. Educational Researcher, 32(8), 26-29.

Kirschner D., \& Whitson J. A. (Eds.) (1997). Situated cognition: Social, semiotic, and psychological perspectives. Mahwah, NJ: Lawrence Erlbaum Associates.

Lehtinen, E. (2003). Computer-supported collaborative learning: An approach to powerful learning environments. In: E. De Corte, L. Verschaffel, N. Entwistle, \& J. van Merriënboer (Eds.), Powerful learning environments: Unravelling basic components and dimensions. Oxford, UK: Elsevier Science Ltd (pp. 35-53). (Advances in Learning and Instruction Series.).

Mayer, R. E. (2001). Changing conceptions of learning: A century of progress in the scientific study of education. In: L. Corno (Ed.), Education across a century: The centennial volume. Hundredth Yearbook of the National Society for the Study of Education (pp. 34-75). Chicago, IL: National Society for the Study of Education.

National Research Council (2000). How people learn: Brain, mind, experience, and school. In: J. D. Bransford, A. L. Brown, \& R. R. Cocking (Eds.), Committee on Developments in the Science of Learning and Committee on Learning Research and Educational Practice. Washington, DC: National Academy Press.

National Research Council (2001). Adding it up: Helping children learn mathematics. In: J. Kilpatrick, J. Swafford, \& B. Findell (Eds.), Mathematics Learning Study Committee, Center for Education, Division of Behavioral and Social Sciences and Education. Washington, DC: National Academy Press. 
National Research Council (2005). How students learn: History, mathematics, and science in the classroom. Committee on How people learn, a targeted report for teachers. In: M. S. Donovan \& J. D. Bransford (Eds.), Division of behavioral and social sciences and education. Washington, DC: National Academy press.

Perkins, D. N. (1995). Outsmarting IQ: The emerging science of learnable intelligence. New York: The Free Press.

Phillips, D. C. (1995). The good, the bad, and the ugly: The many faces of constructivism. Educational Researcher, 24(7), 5-12.

Phillips D. C. (Ed.) (2000). Constructivism in education: Opinions and second opinions on controversial issues. Ninety-ninth yearbook of the national Society for the Study of Education. Part I. Chicago, IL: National Society for the Study of Education.

Phillips, D. C., \& Dolle, J. R. (2006). From Plato to Brown and beyond: Theory, practice, and the promise of design experiments. In: L. Verschaffel, F. Dochy, M. Boekaerts, \& S. Vosniadou (Eds.), Instructional psychology: Past, present and future trends. Sixteen essays in honour of Erik De Corte (pp. 277-292). Oxford, UK: Elsevier Science Ltd. (Advances in Learning and Instruction Series).

Salomon G. (Ed.) (1993). Distributed cognition. Psychological and educational considerations. Cambridge, UK: Cambridge University Press.

Salomon, G., \& Perkins, D. N. (1998). Individual and social aspects of learning. In: P. D. Pearson \& A. Iran-Nejad (Eds.), Review of research in education. Volume 23 (pp. 1-24). Washington, DC: American Educational Research Association.

Sfard, A. (1998). On two metaphors for learning and the dangers of choosing just one. Educational Researcher, 27(2), 4-13.

Shuell, T. J. (1988). The role of the student in learning from instruction. Contemporary Educational Psychology, 13, 276-295.

Simons, R. J., van der Linden, J., \& Duffy, T. (Eds.). (2000a). New learning. Dordrecht, The Netherlands: Kluwer Academic Publishers.

Simons, R. J., van der Linden, J., \& Duffy, T. (2000b). New learning: Three ways to learn in a new balance. In: R. J. Simons, J. van der Linden, \& T. Duffy (Eds.), New learning (pp. 1-20). Dordrecht, The Netherlands: Kluwer Academic Publishers.

Steffe L. P. \& Gale J. (Eds.) (1995). Constructivism in education. Hillsdale, NJ: Lawrence Erlbaum Associates.

van der Linden, J., Erkens, G., Schmidt, H., \& Renshaw, P. (2000). Collaborative learning. In: R.J. Simons, J. van der Linden, \& T. Duffy (Eds.), New learning (pp. 37-54). Dordrecht, The Netherlands: Kluwer Academic Publishers.

Vosniadou, S. (1996). Towards a revised cognitive psychology for advances in learning and instruction. Learning and Instruction, 6, 95-109.

Vosniadou, S. (2001). How children learn. Geneva: International Bureau of Education. (Educational Practices Series, 7).

Vosniadou, S. (2005). The problem of knowledge in the design of learning environments. In: L. Verschaffel, E. De Corte, G. Kanselaar, \& M. Valcke (Eds.), Powerful environments for promoting deep conceptual and strategic learning (pp.19-27). Leuven: Leuven University Press. (Studia Paedagogica, 41).

Vosniadou, S., \& Vamvakoussi, X. (2006). Examining mathematics learning from a conceptual change point of view: Implications for the design of learning environments. In: L. Verschaffel, F. Dochy, M. Boekaerts, \& S. Vosniadou (Eds.), Instructional psychology: Past, present and future trends. Sixteen essays in honour of Erik De Corte (pp. 55-70). Oxford, UK: Elsevier Science Ltd. (Advances in Learning and Instruction Series).

Webb, N. M., \& Palincsar, A. S. (1996). Group processes in the classroom. In: D. C. Berliner \& R. C. Calfee (Eds.), Handbook of educational psychology (pp. 841-873). New York, NY: Macmillan.

Wood, T., Cobb, P., \& Yackel, E. (1991). Change in teaching mathematics: A case study. American Educational Research Journal, 28, 587-616.

Zimmerman, B. J. (1994). Dimensions of academic self-regulation: A conceptual framework for education. In: D. H. Schunk \& B. J. Zimmerman (Eds.), Self-regulation of learning and performance: Issues and educational applications (pp. 3-21). Hillsdale, NJ: Lawrence Erlbaum Associates.

Zimmerman, B. J., \& Risemberg, R. (1997). Self-regulatory dimensions of academic learning and motivation. In: G. D. Phye (Ed.), Handbook of academic learning: Construction of knowledge (pp. 105-125). San Diego, CA: Academic Press. 